\title{
AUTOMATIC GENERATION CONTROL OF A THERMAL POWER PLANT WITH REHEAT TURBINE USING PSO OPTIMIZED INTEGRAL CONTROLLER
}

\author{
Vandana Dhawane \\ Department of Electronics \& Telecommunication, \\ G. H. Raisoni College of Engineering \& Management, Pune, India \\ Rajankumar Bichkar \\ Principal, Vidya Prathishthn's Kamalnayan Bajaj Institute of Engineering \& Technology, India
}

\begin{abstract}
In this paper an approach has been presented for load frequency control of a singlearea thermal power plant with reheat turbine. Integral controller has been preferred for control of manipulated variable of the control system representing a single-area thermal power system, since the basic intention of load frequency control execution is to annihilate the frequency deviation resulting from step load disturbance acting on a power system. The gain of the integral controller is optimized with the help of Particle Swarm Optimization (PSO) technique. Various objective functions such as IAE (Integral Absolute Error), ITAE (Integral Time Absolute Error), ITSE (Integral Time Square Error) and ISE (Integral Square Error) are used as benchmark criteria for optimizing the gain of the controller. The controller performance exhibits divergence based upon objective functions. In the second part of the research, we have tested the system for robustness by administrating the system performance for parameter variations. The simulation results have affirmed the robust performance of the system.
\end{abstract}

Key words: Automatic Generation Control, thermal power plant, reheat turbine, PSO, optimization, robustness.

Cite this Article: Vandana Dhawane and Rajankumar Bichkar, Automatic Generation Control of a thermal power plant with reheat turbine using PSO optimized integral controller. International Journal of Electrical Engineering and Technology, 11(4), 2020, pp. 318-330.

http://iaeme.com/Home/issue/IJEET?Volume=11\&Issue=4

\section{INTRODUCTION}

Load frequency control problem is one of the major and important issues that have been the focus of research since many decades. The quality of the power delivered by a power generation system is a function of frequency, and since major part of the load on an electrical system being 
Automatic Generation Control of a thermal power plant with reheat turbine using PSO optimized integral controller

inductive in nature, frequency control has become vital with reference to the performance of electrical generation power system. Additionally, power demand being increasingly on high rise has resulted in increased intricacy of the power system. Modelling of a complex power system has also posed another challenge for control engineers. Mathematical modelling and design of control logic without deterring the performance of the system is another objective integrated with achievement of frequency control [1].

Different researchers have ventured into the load frequency control dominion with a wide range of control techniques incorporating various architectures such as internal model control schemes [2], fuzzy logic control scheme [3], PID (Proportional Integral Derivative) controllers [4], optimal controllers [5], proportional- Integral- Observer based state feedback controllers [6] and fractional order controllers [7]. PID controller being identified for its robust performance has always been a preferred choice of many control engineers and has also found application for load frequency control purpose. Numerous techniques are available for tuning the gains of PID controller including conventional techniques such as Cohen Coon technique and Zeigler Nichols Technique using process reaction curve or continuous cycling method. However one of the significant disadvantages of Zeigler Nichlos technique and Cohen Coon method is oscillatory behaviour of the resulting system [8]. Hence researchers have come up with various advanced methodologies that are used for efficient tuning of PID controllers. Padhan and Majhi [9] have used Laurent series to identify the gains of the controller. Khodabakshian and Hooshmand [10] have used PID controller for automatic generation control of a hydro-turbine power system. The main idea used for designing the controller is by limiting the peak overshoot of the system response to some finite predetermined value as a result of step change in reference input to a system using Nichols chart. The system so designed guaranteed the stability of the system. Fractional order controllers and internal model control scheme is another widely used and popular control schema in the field of automatic generation control due to their dominating ability of disturbance rejection and capability to handle non-linear systems [11].

Literature study has further unfolded the extensive use of optimization techniques in the field of AGC. Optimization techniques are capable of finding the solution to a problem in the defined search space using nature inspired techniques. Evolutionary algorithms belong to class of evolutionary computation which represents artificial intelligence. Different optimization techniques recorded in literature are Cuckoo search [12], bee's algorithm [13], electimize optimization [14], firefly algorithm [15], and harmony search algorithm [16]. Jain and Hote [17] have used big bang big crunch optimization technique for designing of fractional PID controller. The controller is used for LFC purpose for a single area thermal power system without reheat turbine. Comparison of transient response performance parameters and objective function values has proved the suitability of the approach. Jagatheesan and Anand et al. [18] have applied stochastic particle swarm optimization for optimizing the gains of PI (Proportional Integral) controller applied for LFC purpose of a single-area reheat thermal power system. Arya and Kumar [19] have used bacterial foraging optimization algorithm [BFOA] for optimizing the gains of fractional order fuzzy PID controller. The controller so developed has been used for AGC purpose of two-area multi-source hydrothermal power system. The efficiency of the system was tested for wide variations in loading conditions, system parameter variations and with generation rate constraints. Padhy, et. al. [20] have applied modified grey wolf optimization technique for tuning the gains of cascade PI-PD controller for AGC purpose of a power system in presence of plug in Electric vehicle (PEV). The methodology is tested upon single-area thermal -hydro and gas power plant, two-area six-unit power system and five unequal area non-linear power systems and the performance was validated after comparison with other results published in the literature. 


\section{DESCRIPTION AND MODELLING OF THE SYSTEM}

This section presents the dynamic model for a single-area thermal power plant with reheat turbine.

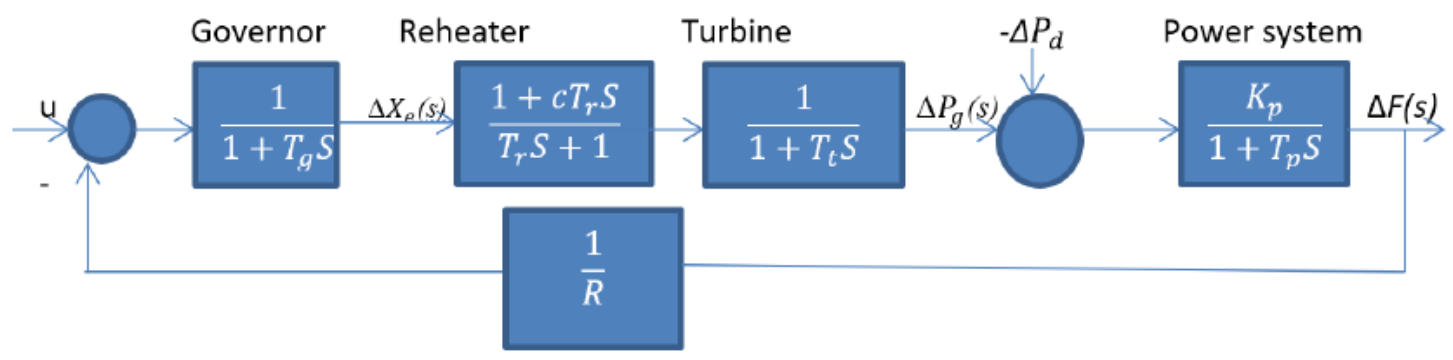

Figure 1 Dynamic model of a single-area thermal power system with reheat turbine

As can be observed from the system depicted in figure 1, the main units of single-area thermal power system with re-heater are governor, turbine with reheated stage, power system which represents load and machine and droop characteristic represented by regulation R [21]. The regulation $\mathrm{R}$ is a negative feedback used for frequency damping in response to sudden load disturbance on the system. The nomenclature for different parameters of a thermal power system with reheated turbine is given in table 1. [22][23][24].

Table 1 Nomenclature for power system parameters

\begin{tabular}{|ll|}
\hline$T_{p}$ & Power system time constant (Sec) \\
\hline$R$ & Regulation parameter (Hz/p.u.MW) \\
\hline$\Delta P_{d}$ & Load disturbance (p. u. MW) \\
\hline$T_{t}$ & Turbine time constant (Sec) \\
\hline$c$ & percentage of power generated in reheated section \\
\hline$T_{g}$ & Governor time constant (Sec) \\
\hline$u$ & Incremental change in reference power setting (p.u. MW) \\
\hline$K_{p}$ & Power system gain (Hz/p. u. MW) \\
\hline$\Delta P_{g}(s)$ & Incremental change in generator power output (p. u. MW) \\
\hline$\Delta F$ & Incremental frequency deviation (Hz) \\
\hline$\Delta X_{e}(s)$ & Incremental change in governor valve position \\
\hline$T_{\mathrm{r}}$ & Constant of reheat turbine \\
\hline
\end{tabular}

The transfer function representation of the thermal power system with reheat turbine in Laplace domain can be represented by the following equation [25]:

$$
G(s)=\frac{G_{t}(s) G_{g}(s) G_{p}(s)}{1+G_{t}(s) G_{g}(s) G_{p}(s) / R}
$$

Turbine dynamics for a steam turbine with reheater is defined by $G_{t}(\mathrm{~s})$ and is given as:

$$
G_{t}(\mathrm{~s})=\frac{c T_{r} S+1}{\left(T_{r} S+1\right)\left(T_{t} S+1\right)}
$$

$G_{g}(\mathrm{~s})$ represents governor dynamics and is given by the equation:

$$
G_{g}(\mathrm{~s})=\frac{1}{1+T_{g} S}
$$

Power system dynamics is given by:

$$
G_{p}(\mathrm{~s})=\frac{K_{p}}{1+T_{p} S}
$$


Automatic Generation Control of a thermal power plant with reheat turbine using PSO optimized integral controller

For the reheated turbine, the parameter values are given below:

$$
K_{p}=120, T_{p}=20, T_{g}=0.08, T_{t}=0.3, T_{r}=4.2, R=2.4, c=0.35
$$

\section{INTEGRAL CONTROLLER DESIGN}

When the system is subjected to a sudden load disturbance of magnitude 0.01 p.u., the frequency of the system deviates from nominal value with a peak undershoot and settles at a new steady state value determined by the magnitude of load and droop value $R$. Whereas in case of the power system equipped with secondary controller, the deviations in the frequency are nullified and system frequency goes back to its nominal value after the oscillations have damped.

In our proposed work, we have selected integral controller for frequency regulation, since the controller has the capability of reducing steady state deviation in the controlled variable to zero. The transfer function for integral controller in Laplace domain is given as [26]:

$$
G_{c}(\mathrm{~s})=\frac{K_{i}}{S}
$$

In which $K_{i}$ represents integral gain. The integral controller accounts for the past values of errors integrating them over time to produce control signal which accordingly changes the manipulated variable driving the error in controlled variable to zero. In time domain the integral control action can be given as:

$$
u(t)=K_{i} \int_{0}^{t} e(t) d t
$$

Where, $K_{i}$ is the integral gain. In an integral controller, the magnitude of the response by the integral term is the cumulative effect of magnitude of error as well as time duration for which the error exists.

\section{PARTICLE SWARM OPTIMIZATION}

Particle swarm optimization is one of the popular evolutionary optimization techniques developed by Kennedy and Eberhart. The working of the algorithm is influenced by social behaviour of organisms such as birds or fish which move together interacting with each other to share information. The algorithm reaches for the optimal solution within the search space through particles whose direction of movement is influenced by stochastic and deterministic elements [27]. PSO is a preferred choice for optimization purpose since it requires tuning of fewer variables. PSO can be applied in various forms including classical, heuristic and with many variants to suit the application or complexity of the problem. The goal of optimization is to determine the optimal value of the vector $X=\left[\begin{array}{llll}x_{1} & x_{2} & x_{3} & x_{n}\end{array}\right]$ that represents a variable in the defined problem. The variable $X$ is n-dimensional vector called as position vector in which, $n$ denotes the number of variables to be determined by the optimization process. An objective function or fitness function is used for assessment of the solution resulting from the optimization process. Consider a swarm comprising of $P$ particles. The position vector $X$ and velocity vector $V$ are used for representing position and velocity of each particle in the swarm at a particular iteration.

$$
X_{j}^{t}=\left[\begin{array}{lll}
x_{j 1} x_{j 2} x_{j 3} & x_{j n}
\end{array}\right]
$$

The position vector $X_{j}^{t}$ gives the position of $j^{\text {th }}$ particle in $n$-dimensional search space at $\mathrm{t}$ iteration.

$$
V_{j}^{t}=\left[\begin{array}{llll}
v_{j 1} & v_{j 2} & v_{j 3} & v_{j n}
\end{array}\right]
$$


The velocity vector $V_{j}^{t}$ represents velocity of particle $j$ at t iteration. A particle $j$ is defined by its velocity vector $V_{j}$ and position vector $X_{j}$.

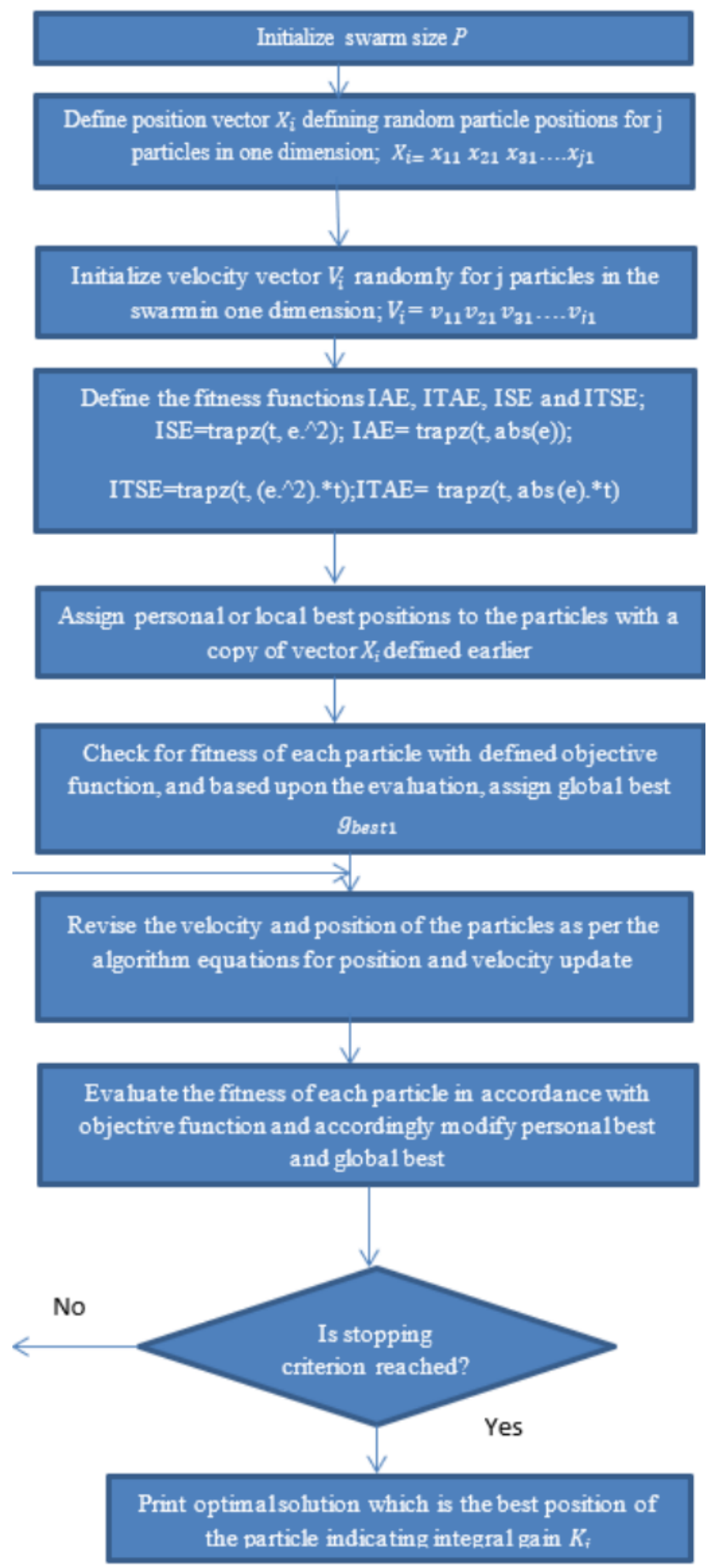

Figure 2 Particle swarm optimization

The movement of every particle in the search space in affected by its own best position called as local best compared to previous positions attained so far by the particle and is given 
Automatic Generation Control of a thermal power plant with reheat turbine using PSO optimized integral controller

as pbest $_{j k}$. Here, $j=1,2, \ldots, P$ and $k=1,2, \ldots, n$. Similarly the best position attained so far by the swarm as a whole regardless of which particle has achieved, is called as global best and is given as gbest $_{j}$.

The position and velocity vectors are updated through dimensions $k$ as per the following equations:

$$
\begin{gathered}
X_{j k}^{t+1}=X_{j k}^{t}+V_{j k}^{t+1} \\
V_{j k}^{t+1}=\omega V_{j k}^{t}+c_{1} r_{1}\left(\text { pbest }_{j k}-X_{j k}^{t}\right)+c_{2} r_{2}\left(\text { gbest }_{j}-X_{j k}^{t}\right)
\end{gathered}
$$

Equation (8) is used for updating particle's position. Equation (9) denotes that the particle movement in the swarm is an attribute of three main factors during iteration. The parameter $\omega$ is called as inertia weight constant which is a positive constant value. It is attributed for keeping constant, the particle search in the direction of previous motion. The inertia constant is also responsible for balancing the local search called as exploitation and global search called as exploration. The value of $\omega=1$ indicates the particle motion in previous direction. On the other hand, $0 \leq \omega<1$ implies reduced influence of inertia constant indicating freedom of the particle to explore other regions in the search space increasing the probability of finding global optimum at the cost of increased simulation time. The second term of equation (9) is called as cognition term and is calculated by the difference between the own best position of the particle $p_{b e s t} t_{j k}$ and its current position $X_{j k}^{t}$. The idea behind this term is that as the particle tends to drift away from its personal best position, the value of the difference term $\left(\right.$ pbest $\left._{j k}-X_{j k}^{t}\right)$ increases leading to movement of the particle to its own best position. The parameter $c_{1}$ is a positive constant and it called as individual-cognition parameter and it signifies the importance of the previous personal experiences of the particle. Its value is generally in the range $[0,2]$. The second term is composed of one more parameter $r_{1}$ which is a random value parameter in the $[0,1]$. The third component of equation (9) is called as social component. The component acts as an agent for sharing information between the particles regarding the best position found so far by the swarm irrespective of which particle has found it. The difference $\left(g b e s t_{j}-X_{j k}^{t}\right)$ tends to attract the particle to a point which has highest fitness with respect to the entire swarm. Similar to earlier case, $c_{2}$ is a social learning parameter in the range $[0,2]$ and it weighs the global learning capability of the swarm. The role of $r_{2}$ is same as that of $r_{1}[28]$.

\section{RESULT EVALUATION AND DISCUSSION}

In this section, we have presented the analysis of the results obtained by the proposed PSO optimized Integral controller used for AGC of a single-area thermal power plant with reheat turbine. The objective functions used for evaluation of the algorithm are:

$$
\begin{aligned}
& \text { IAE }=\int_{0}^{t}|e(t)| d t \\
& \text { ITAE }=\int_{0}^{t} t|e(t)| d t \\
& \text { ISE }=\int_{0}^{t}\left(e(t)^{2}\right) d t \\
& \text { ITSE }=\int_{0}^{t} t \cdot e(t)^{2} \mathrm{dt}
\end{aligned}
$$

Following are the values considered during implementation of the algorithm:

Swarm size $=40, c_{1}=c_{2}=2.0, \omega=1$, no. of iterations $=50$

The standard values of parameters for a single-area thermal power plant with reheat turbine are given as: 


$$
K_{p}=120, T_{t}=0.3, T_{p}=20, \mathrm{R}=2.4, T_{g}=0.08, \mathrm{c}=0.35, T_{r}=4.2
$$

\subsection{Case1: System with nominal system parameters}

In this part of evaluation, we have considered a single-area thermal power system with reheat turbine with nominal system parameters. The simulation response is plotted when the system experiences a sudden load disturbance of magnitude $0.01 \mathrm{p}$. u. As a result of load change, the initial action is taken by the governor leading to a steady state error in the frequency. The integral controller due to its secondary control action reduces this deviation to zero, restoring the frequency back to its nominal value. The system under study has been simulated and investigated for its performance in MATLAB 2014a environment. For the purpose of frequency response evaluation we have considered four objective functions viz: IAE, ISE, ITAE and ITSE. The efficiency of different objective functions is assessed based upon the values of transient response performance parameters. Different objective function display different convergence pattern while reaching the optimal solution. Figures [3] [4] [5] and [6] shows the convergence profile for various objective functions for nominal system parameters.

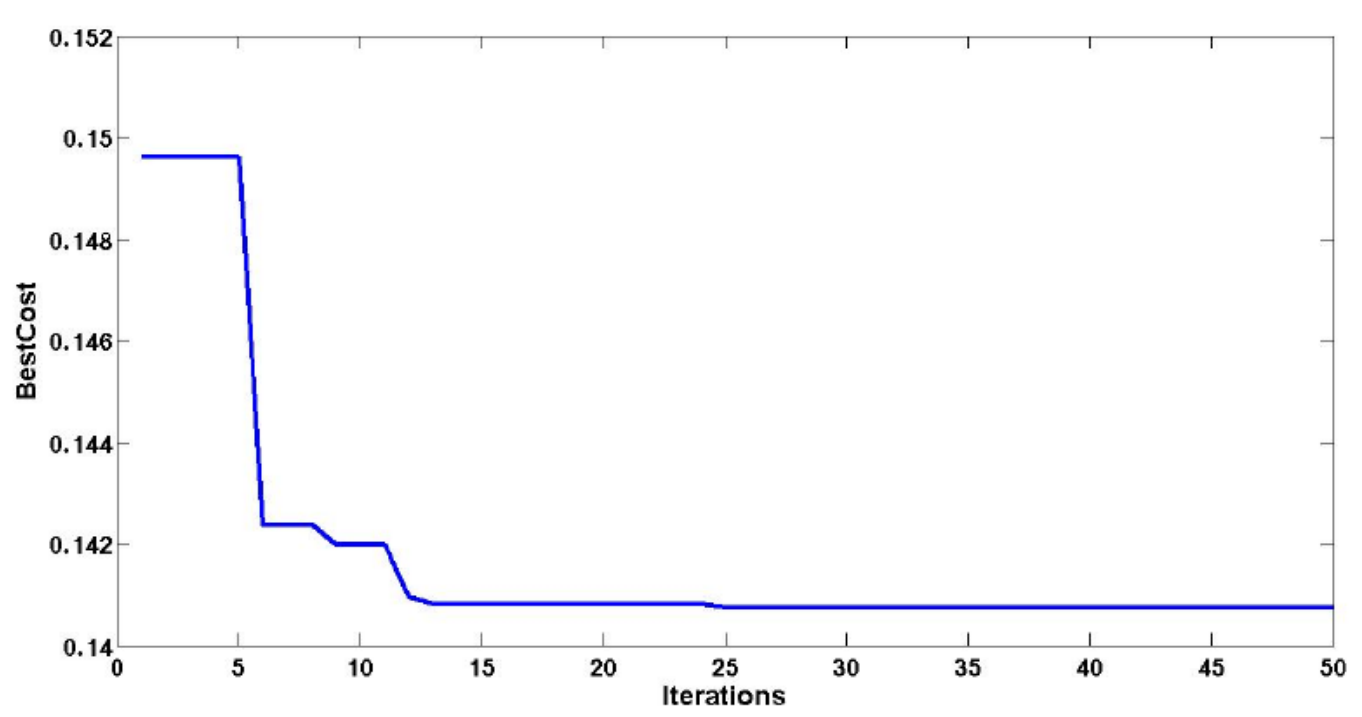

Figure 3 Convergence pattern for IAE cost function for nominal system parameters

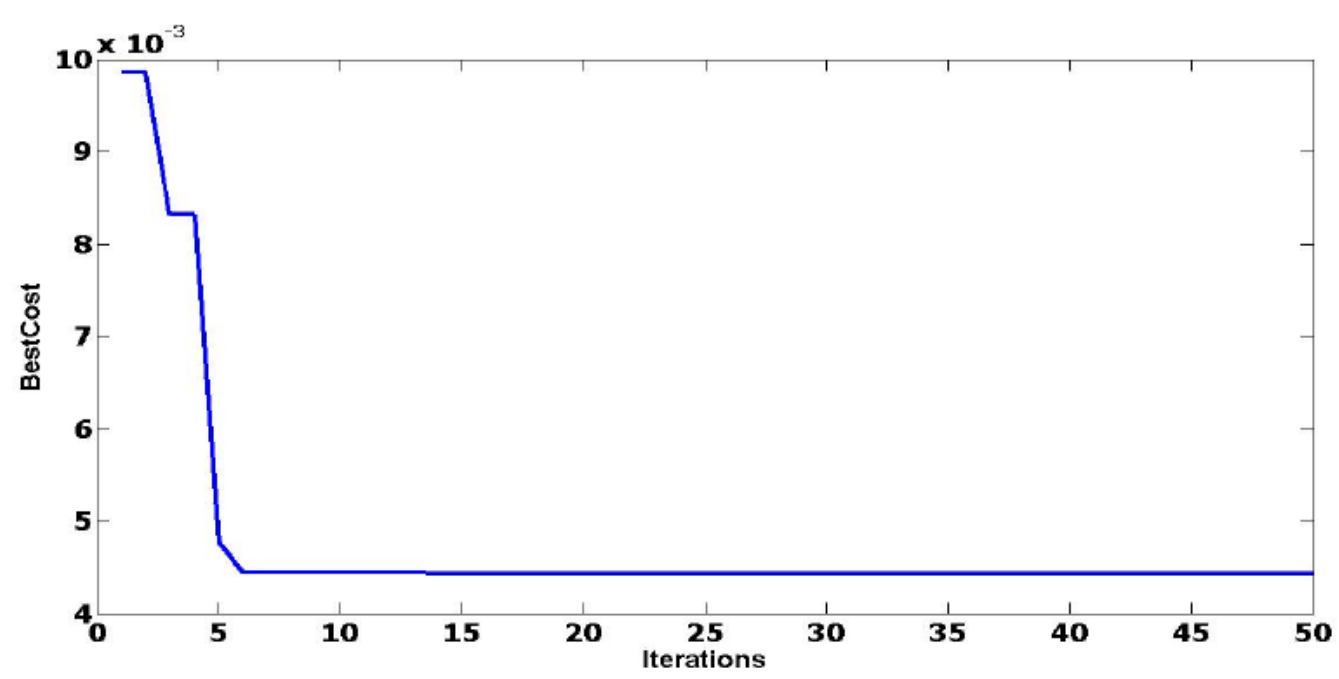

Figure 4 Convergence pattern for ISE cost function for nominal system parameters 
Automatic Generation Control of a thermal power plant with reheat turbine using PSO optimized integral controller

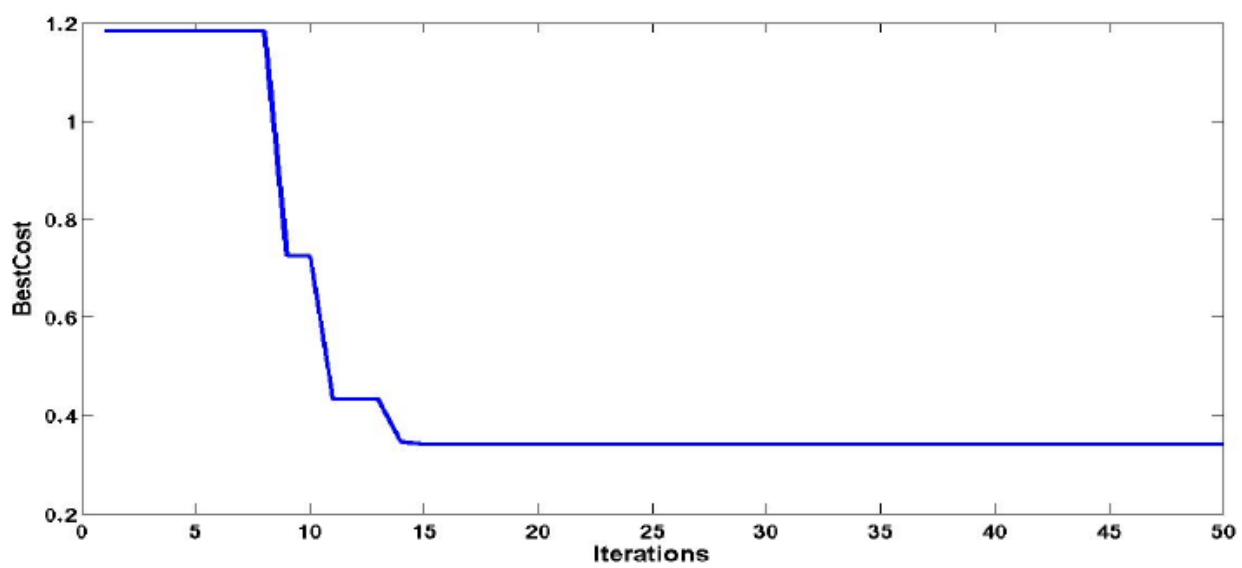

Figure 5 Convergence pattern for ITAE cost function for nominal system parameters

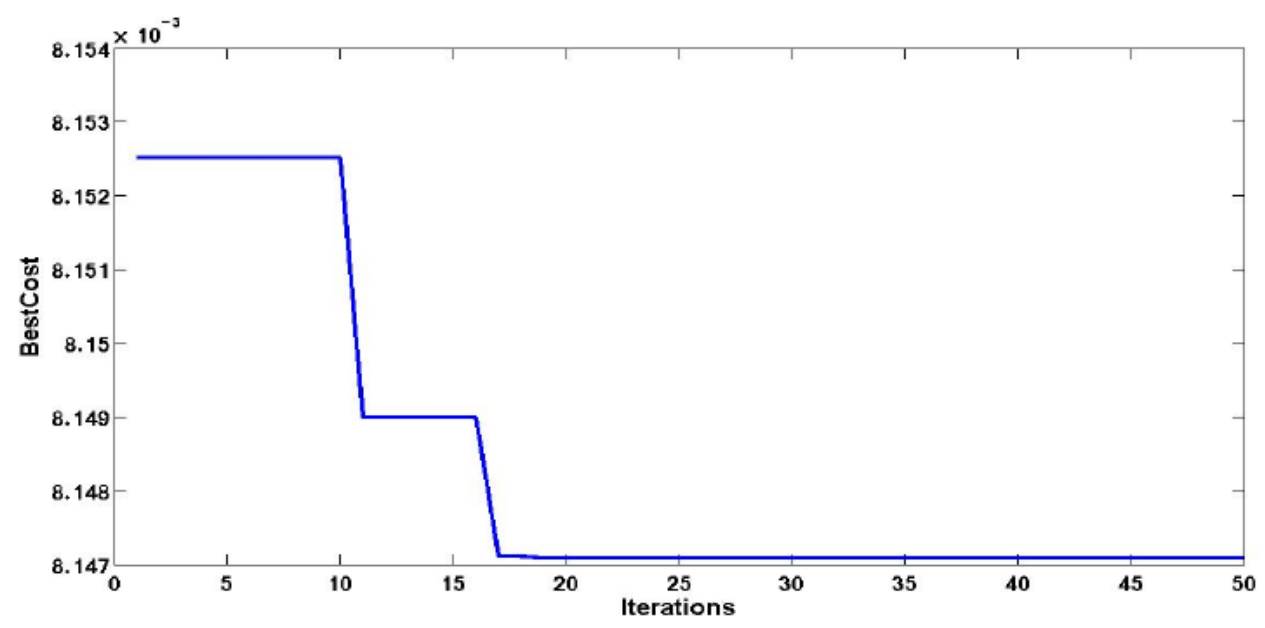

Figure 6 Convergence pattern for ITSE cost function for nominal system parameters

Figure 7 below displays the step response of the system with nominal system parameters, when the system is subjected to a sudden step load disturbance with different objective functions used for optimization of the controller. As can be seen from the response, the transient response varies with the objective function used for optimization of the integral controller. The values of performance parameters indicating the quality of transient response differ with objective functions. Table 2 below displays the values of various parameters along with integral gain $K_{i}$ for a system with nominal system parameters

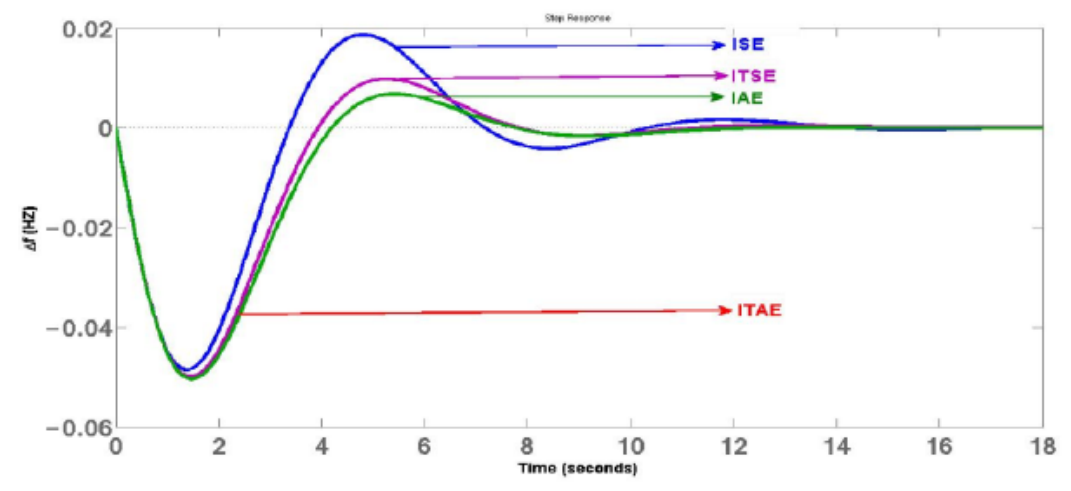


Figure 7 Frequency deviation step response for nominal system parameters.

Table 2 Transient response performance values for a system with nominal parameters

\begin{tabular}{|lcccccc|}
\hline Cost function & $K_{i}$ & Rise time $\left(T_{r}\right)$ & Peak Time $\left(T_{P}\right)$ & Settling Time $\left(T_{S}\right)$ & Peak value & Performance index \\
& & $(\mathrm{Sec})$ & $(\mathrm{Sec})$ & $(\mathrm{Sec})$ & $(\mathrm{Hz})$ & \\
ISE & 0.15892 & 0.0023 & $\mathbf{1 . 3 6 6 8}$ & 13.1527 & $\mathbf{0 . 0 4 8 6}$ & 0.0044398 \\
ITAE & 0.08778 & $\mathbf{0 . 0 0 0 0 3}$ & 1.4819 & 10.5508 & 0.0504 & 0.3404727 \\
ITSE & 0.10404 & 0.0195 & 1.4630 & 10.5868 & 0.0500 & 0.0081471 \\
IAE & 0.088617 & 0.0013 & 1.4809 & $\mathbf{1 0 . 5 4 5 1}$ & 0.0504 & 0.1407374 \\
\hline
\end{tabular}

Bold figures indicate best values for a selected response parameter

\subsection{Case 2: System with parameter variations}

To verify the proposed technique for its robustness, we have introduced a $50 \%$ deviation in system parameters in both upper and lower bound and verified the system performance for transient response with different objective functions. The parameters values considered for upper and lower bound are as given below:

$$
\begin{gathered}
K_{p}=[180,60], T_{t}[0.15,0.45], T_{g}=[0.04,0.12], T_{p}=[1030], \mathrm{c}=[0.175,0.525], T_{r}=[2.1,6.3] \\
\mathrm{R}=[1.2,3.6] .
\end{gathered}
$$

Figure 8 and figure 9 shows the transient response when the system parameters are varied in 50\% upper bound and 50\% lower bound respectively. Table 3 displays the results tabulated for various transient response performance parameters for system parameter variations. As seen from table 3, ITSE cost function gives a lowest settling time of 8.778 seconds causing the system frequency to settle fast to the nominal value when disturbance occurs at the system while system parameters are subjected to $50 \%$ deviation in upper limit. Similarly a minimum peak deviation of $0.0566 \mathrm{~Hz}$ occurs with ISE cost function when subjected to system parameter changes in upper bound with lowest value of rise time equal to 0.002 seconds indicating a speedy response of the system.

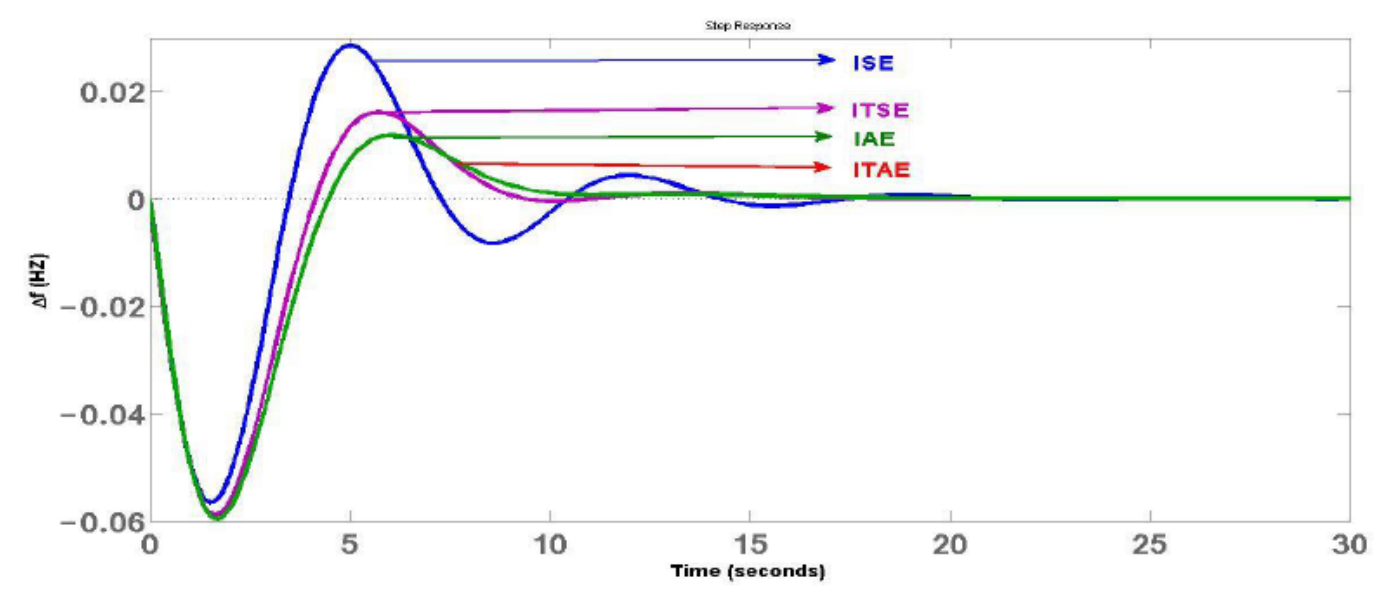

Figure 8 Transient response for system parameter changes in 50\% upper bound 
Automatic Generation Control of a thermal power plant with reheat turbine using PSO optimized integral controller

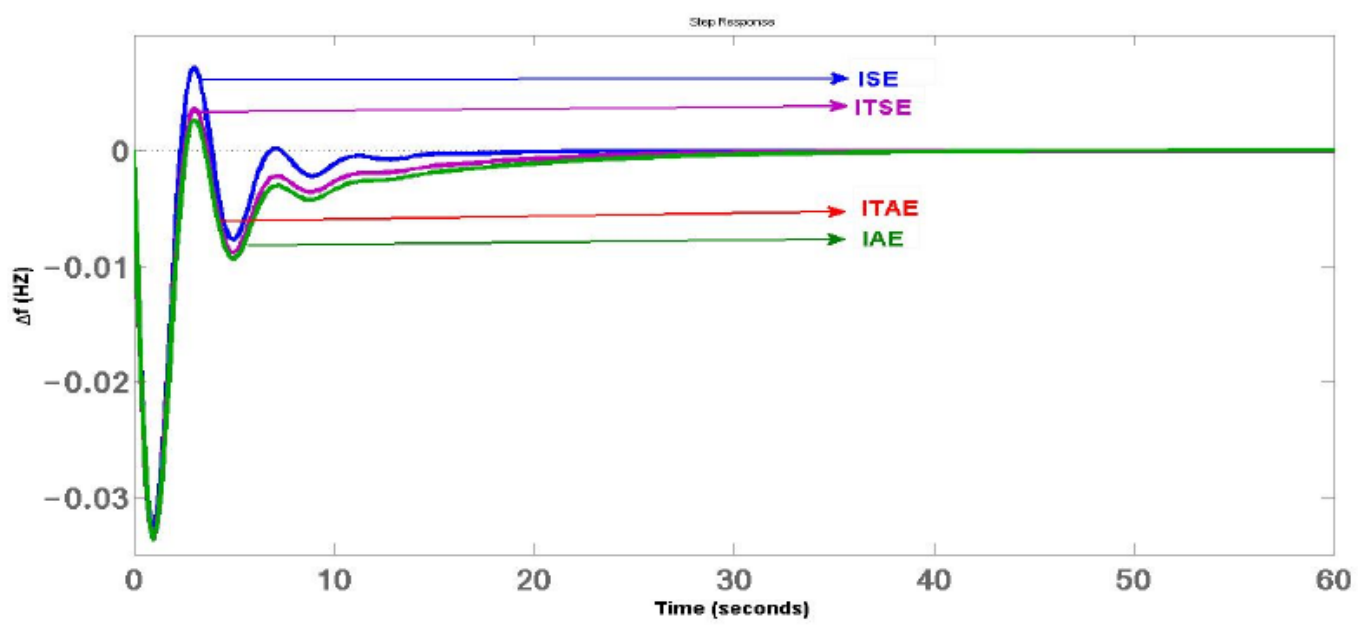

Figure 9 Transient response for system parameter variations in 50\% lower bound

Transient performance parameters for system parameter variations

\begin{tabular}{|lcccccccc|}
\hline Cost function & \multicolumn{4}{c}{$50 \%$ upper bound } & \multicolumn{4}{c|}{$50 \%$ lower bond } \\
\hline & $T_{r}$ & $T_{p}$ & $T_{s}$ & Peak & $T_{r}$ & $T_{p}$ & $T_{s}$ & Peak \\
\hline ISE & $\mathbf{0 . 0 0 2}$ & $\mathbf{1 . 5 2 3}$ & 16.218 & $\mathbf{0 . 0 5 6 6}$ & 0.004 & $\mathbf{0 . 8 6 7}$ & $\mathbf{1 0 . 3 0 7}$ & $\mathbf{0 . 0 3 3 1}$ \\
\hline ITAE & 0.008 & 1.717 & 9.738 & 0.0596 & 0.0005 & 0.972 & 24.676 & 0.0338 \\
\hline IAE & 0.008 & 1.712 & 9.712 & 0.0596 & $\mathbf{0 . 0 0 0 4}$ & 0.973 & 24.578 & 0.0338 \\
\hline ITSE & 0.004 & 1.683 & $\mathbf{8 . 7 7 8}$ & 0.0588 & 0.0031 & 0.996 & 18.614 & 0.0337 \\
\hline
\end{tabular}

Bold figures indicate best values for a selected response parameter

For the case of system parameter changes in lower bound, system settles faster with a minimum settling time of 10.307 seconds with ISE cost function. The consideration of peak frequency deviation shows that the value of frequency deviation is not affected considerably with objective function. The bar graphs shown in figures [10] [11] [12] and [13] depicts the relative comparison between various transient performance indices for different objective functions for nominal system parameters as well as system parameter variations in upper and lower limit.

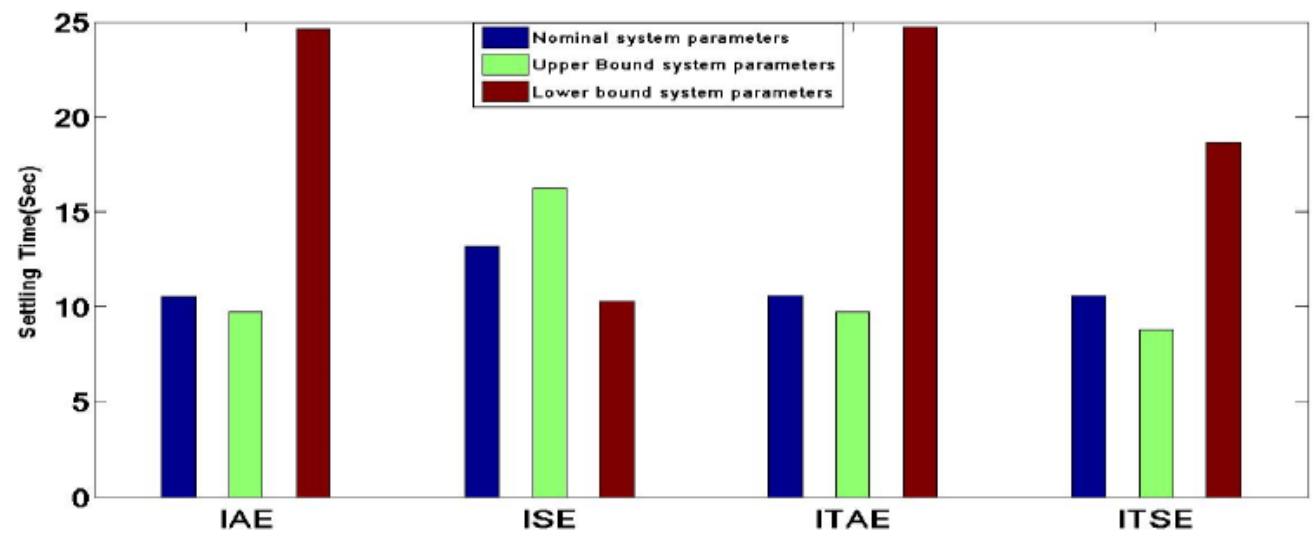

Figure 10 Settling time comparison for various objective functions 


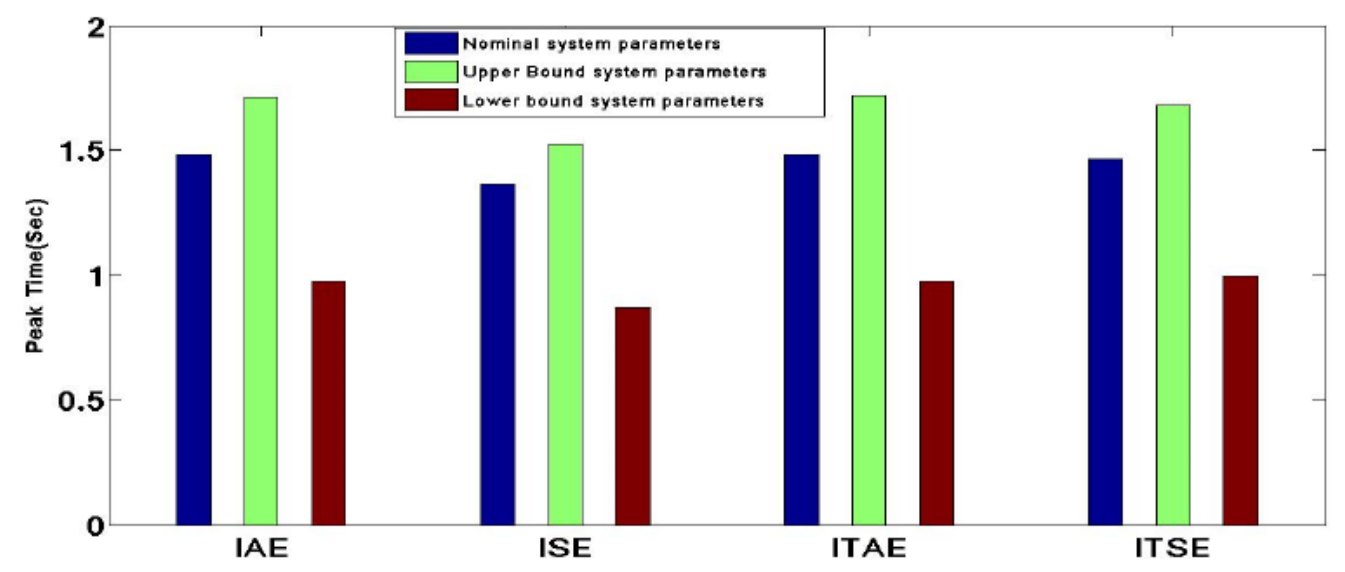

Figure 11 Peak time comparison for various objective functions

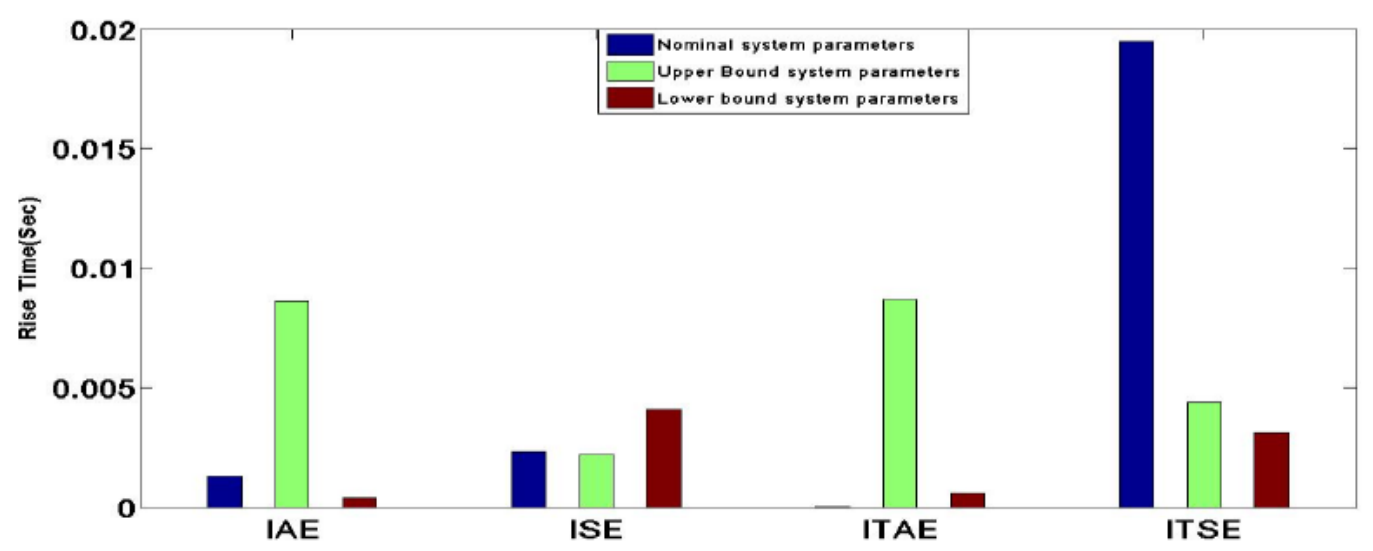

Figure 12 Rise time comparison for various objective functions

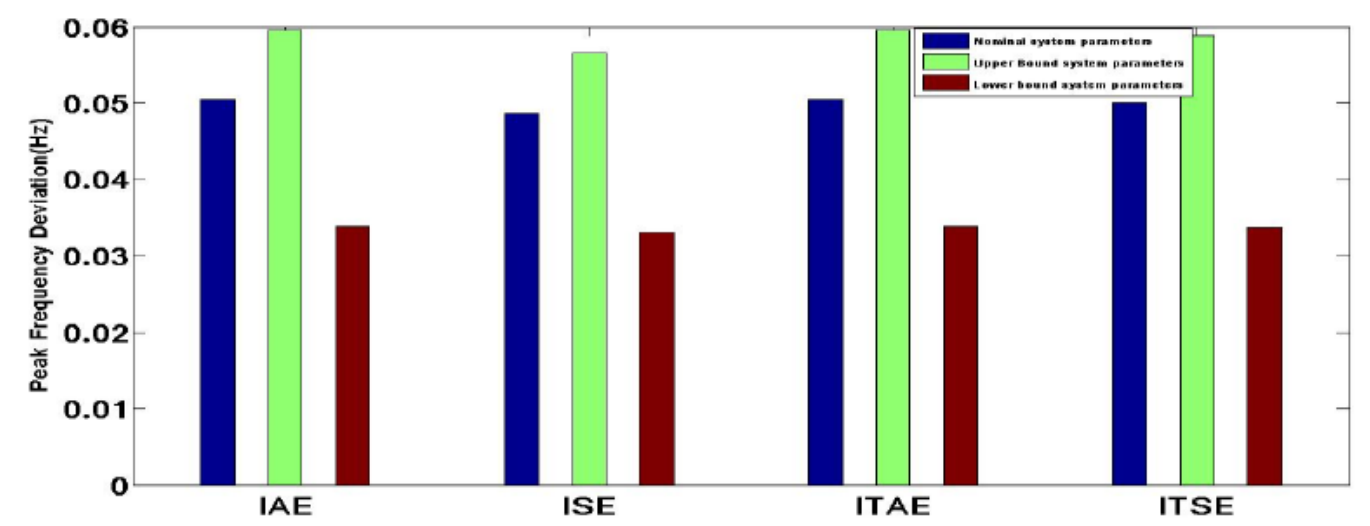

Figure 13 Peak frequency deviation for various objective functions

As is revealed from the observations in figures [10] - [13], lowest value of settling time equal to 10.5451 second is obtained with IAE objective function for nominal system parameters. Similarly ITAE cost function gives lowest value of rise time equal to 0.00003 second, while ISE cost function gives minimum value of peak time equal to 1.3668 for a system with nominal system parameters. 
Automatic Generation Control of a thermal power plant with reheat turbine using PSO optimized integral controller

\section{CONCLUSION}

In the present study, we have considered a single-area thermal power system with reheat turbine. PSO optimized integral controller is used for AGC purpose of the said system when the system experiences sudden load disturbance. Different objective functions are used for optimizing the gains of the controller and a comparative study of performance analysis of these objective functions is done based upon transient response performance parameters such as settling time, rise time and peak frequency deviation. The study reveals that the system performance in terms of rise time and settling time is affected by the type of performance index selected for optimization purpose. However peak frequency deviation does not show significant variations. Similarly the system is found to be robust when subjected to disturbances in presence of system parameter variations. The comparative performance analysis of system response in case of system parameter variations prove that the response parameters obtained are well within the limits showing deviations within the permissible range.

\section{REFERENCES}

[1] Saxena, S. Load frequency control strategy via fractional-order controller and reduced-order modelling. Electrical Power and Energy Systems, 104, 2019, pp. 603-614.

[2] Singh, J., Chatterjee, K., and Vishwakarma, C. Two degree of freedom internal model control-PID design for LFC of power systems via logarithmic approximations. ISA Transactions, 2017.

[3] Anwar, M.S., Sheikh, M.R.I., Hossain, M. F., Rabbani, M. G., and Nasiruzzaman A.B.M. Fuzzy gain scheduling of an AGC in a single-area power system. $4^{\text {th }}$ International Conference on Electrical and Computer Engineering, ICECE, 2006.

[4] Oonsilvilai, A., Marungsri and Boonruang. Optimal PID tuning of AGC system using Adaptive Tabu Search. Intellectual Repository, Suranaree University of Technology, 2007.

[5] Al- Hamouz, Z., Al-Duwaish, H., and Al-Musabi, N. Optimal design of a sliding mode AGC controller: Application to a non-linear interconnected model. Electrical Power Systems Research, 81, 2011, pp. 1403-1409.

[6] Hussein, A., Salih, S. and Ghasm, Y. Implementation of proportional-integral-observer techniques for load frequency control of power systems. $7^{\text {th }}$ International Conference on Sustainable Energy Information Technology, SEIT 2017.

[7] Morsali, J., Zare, K., and Hagh, M. Applying fractional order PID to design TCSC-based damping controller in coordination with automatic generation control of interconnected multi-source power system. Engineering Science and Technology, an international journal. 20, 2017, pp. 1-17.

[8] Tavakoli, S. and Tavakoli, M. Optimal tuning of PID controllers for first order plus time delay models using dimensional analysis. Fourth International Conference on Control and Automation, ICCA, Montreal, Canada.

[9] Padhan, D. and Majhi, S. A new control scheme for PID load frequency controller of singlearea and multi-area power systems. ISA Transactions. 52, 2013, pp. 242-251.

[10] Khodabakhshian, A. and Hooshmand, R. A new PID controller design for automatic generation control of hydro power systems. Electrical Power and Energy Systems. 32 2010, pp. 375-382.

[11] Sondhi, S. and Hote, Y. Fractional order PID controllers for load frequency control. Energy Conversion and Management. 85, 2014, pp. 343-353.

[12] Ahmed, T., Chaine, S. and Tripathy, M. Design of optimal SMES for automatic generation control of two-area thermal power system using cuckoo search algorithm. Journal of Electrical Systems and Information Technology. 2, 2015, pp. 1-13. 
[13] Alobaidi, S., and Hamad, A. Exploration-balanced bees algorithm to solve optimization and NP-complete problems. International Journal of Research and Reviews in Soft Intelligent Computing. 2, 2012.

[14] Abdel-Raheem, $M$ and Khalafallah, A. Introduction of a new optimization mechanism for electimize. $13^{\text {th }}$ International Conference on Computer Modelling and Simulation. 2011.

[15] Yang, X. Firefly algorithm, stochastic test functions and design. International Journal of Bio-Inspired Computation. 2, 2010, pp. 78-84.

[16] Shiva, C. and Mukherjee, V. A novel quasi-oppositional harmony search algorithm for automatic generation control of power system. Applied Soft Computing. 35, 2015, pp. 749765.

[17] Jain, S. and Hote, Y. Design of fractional PID for load frequency control via internal model control and big-bang big crunch optimization. IFAC PapersOnline.51, 2018, pp. 610-615.

[18] Jagatheesan, K., Anand, B., Dey, N., Gaber, T., Hassanien, A., and Kim, T. A design of PI controller using stochastic particle swarm optimization in load frequency control of thermal power systems. Fourth International Conference on Information Science and Industrial Applications. 2015.

[19] Arya, Y. and Kumar, N. BFOA-scaled fractional order fuzzy PID controller applied to AGC of multi-area multi-source electric power generating systems. Swarm and Evolutionary Computation. 32, 2017, pp. 202-218.

[20] Padhy, S., Panda, S., and Mahapatra, S. A modified GWO technique based cascade PI-PD controller for AGC of power systems in presence of plug in electric vehicles. Energy Science and Technology, an International Journal. 2017.

[21] P. Kundur. Power System Stability and Control, New York: McGraw-Hill, 1994.

[22] Ismayil, C., Sreeama, K., and Sinhdu, T. Automatic generation control of single area thermal power system with fractional order $\mathrm{PID}\left(\mathrm{PI}^{\kappa} \mathrm{D}^{\mu}\right)$ controllers. IFAC Proceedings. 47 , 2014, pp. 552-557.

[23] Chown, G. and Hartman, R. Design and experience with a fuzzy logic controller for automatic generation control (AGC). IEEE Transactions on Power Systems. 13, 1998.

[24] Singh, V., Kishor, N., and Samuel, P. Improved load frequency control of power system using LMI based PID approach. Journal of the Franklin Institute. 2017.

[25] Elgerd, O. Electric Energy Systems Theory: An introduction, Tata McGraw-Hill, 1983.

[26] Gopal, M. Control Systems: Principles and Design, Tata McGraw-Hill Education, 2002.

[27] Deb, K. Multi-objective Optimization using Evolutionary Algorithms, John Wiley and Sons, 2001.

[28] Seixas, B., Almeida, G., and CoppoLeite, V. Particle swarm optimization: A powerful technique for solving engineering problems. Chapter, Swarm Intelligence-Recent Advances, New Perspectives and Applications, 2019.

[29] Shameem Akthar, Dr. D Rajaylakshmi and Dr. Syed Abdul Sattar, A Modified PSO Based Graph Cut Algorithm for the Selection of Optimal Regularizing Parameter in Image Segmentation, International Journal of Advanced Research in Engineering and Technology (IJARET), Volume 4, Issue 3, April (2013), pp. 273-279. 